\title{
В.В. Ясельская
}

\section{НЕКОТОРЫЕ ПРОБЛЕМЫ ПРОВЕДЕНИЯ ЗАЩИТНИКОМ ОПРОСА ЛИЦ С ИХ СОГЛАСИЯ}

\begin{abstract}
Проведен сравнительный анализ между допросом свидетелей следователем и опросом адвокатом - защитником лиц с их согласия, выявлены сходства и существенные отличия меду ними. Автором определено основание опроса лиц защитником, рассмотрены вопросы регламентации порядка проведения данного действия и внесены предложения по совершенствованию норм УПК РФ.
\end{abstract}

Ключевые слова: адвокат-защитник, следователь, предварительное расследование, допрос свидетелей, опрос лии с их согласия.

УПК РФ, впервые предоставив защитникам право опрашивать лиц, существенно расширил их возможности на стадии предварительного расследования. Как отмечалось в юридической литературе, в период действия УПК РСФСР всякая инициатива защитника в поиске новых доказательств и попытка их фиксации воспринимались органом предварительного расследования как незаконное противодействие [1, с. 51 ; 2 , c. 47]. Защитник не имел права встречаться со свидетелями и беседовать с ними до слушания дела, выяснять что-либо по делу. Сам факт беседы служил основанием для возбуждения дисциплинарного производства в отношении адвоката. [3, с. 4] Кроме того, к свидетелям, с которыми предварительно беседовал защитник, суд относился предвзято. Отсутствие права защитника опрашивать лиц отражалось на активности адвокатов и эффективности участия защитника в уголовном судопроизводстве в целом. Сложно себе представить, как, не опросив лиц, которым могут быть известны сведения, необходимые для защиты обвиняемого, возможно сформировать позицию по делу, проверить доказательства, полученные следователем, заявить ходатайство о вызове и допросе свидетеля защиты и надлежащим образом подготовиться к предстоящему судебному разбирательству.

УПК РФ данную проблему разрешил, закрепив в ч. 3 ст. 86 право защитника собирать доказательства, в том числе опрашивать лиц с их согласия. Однако в законе не определены основание и порядок проведения данного действия защитником.

Советом Федеральной палаты адвокатов РФ в 2004 г. были одобрены методические рекомендации по реализации прав защитника, предусмотренных в ч. 3 ст. 86 УПК РФ, в частности по проведению опроса лиц с их согласия [4]. Однако данные рекомендации не носят нормативного характера и являются выработанными наукой и практикой, в связи с чем, в юридической литературе высказывается предложение нормативно закрепить порядок производства и фиксации результатов опроса адвокатом лиц с их согласия [5, c. 18]. Так, по мнению А.В. Рагулина, отсутствие нормативного характера положений, связанных с производством опроса, негативно влияет на возможность реализации соответствующего правомочия на практике и на возможность использования результатов опроса в процессе доказывания [6, с. 50]. Кроме того, рекомен- дации Федеральной палаты адвокатов по проведению опроса лиц защитником, не содержат конкретных предложений по организации и порядку проведения данного действия (в основном они посвящены порядку фиксации результатов опроса).

В указанных выше рекомендациях отмечено, что действия, которые проводит защитник, по существу отличаются от действий, которые осуществляют органы предварительного следствия и суд при собирании доказательств [4].

Для того чтобы уяснить суть данного действия и определить оптимальный порядок его проведения, необходимо провести четкое разграничение между допросом свидетеля следователем на стадии предварительного расследования и опросом лица защитником, проанализировать сходства и отличия между ними.

Так, в основе допроса свидетеля и опроса лиц лежат одни и те же познавательные приемы. Разделяем позицию С.А. Шейфера, что познавательную основу допроса составляет операция расспроса. Наблюдение же (мимики, жестов) допрашиваемого играет вспомогательную роль, позволяя следователю лучше уяснить смысл словесного сообщения [7, с. 85]. При проведении опроса лиц защитник использует аналогичные приемы: ставит перед опрашиваемым задачу на воспроизведение и передачу запечатленной в его памяти информацию об обстоятельствах, оправдывающих обвиняемого либо смягчающих наказание в устной форме. А также защитник использует вспомогательный прием - наблюдение, что также играет немаловажную роль при проведении данного действия. Так, по невербальным жестам, мимике защитник может, в частности, оценить правдивость информации, предоставленной опрашиваемым лицом.

Кроме того, определенные черты сходства имеются в основаниях производства допроса свидетеля следователем и опроса лиц с их согласия защитником. Так, основанием для допроса свидетеля являются данные о том, что ему известны обстоятельства, имеющие значение для расследования и разрешения дела (ч. 1 ст. 56 УПК РФ).

В УПК РФ основание проведения опроса защитником лиц не определено, содержится лишь условие должно быть согласие лица, которого возникла необходимость опросить (п. 2 ч. 3 ст. 86 УПК РФ). Согласно п. 2 ч.3 ст. 6 Ф3 «Об адвокатской деятельности и 
адвокатуре в РФ, адвокат вправе опрашивать с их согласия лиц, предположительно владеющих информацией, относящейся к делу, по которому адвокат оказывает юридическую помощь» [8].

Представляется, что подобная формулировка закона не позволяет разграничить основание для проведения допроса свидетеля и опроса лица, а также может привести к злоупотреблениям со стороны адвокатов, оказывающих юридическую помощь по уголовному делу. Задача защитника состоит в том, чтобы выявлять обстоятельства, оправдывающие обвиняемого, подозреваемого либо смягчающие их наказание. И основанием для проведения защитником опроса должны быть данные о том, что лицо располагает информацией о существенных обстоятельствах дела, имеющих значение для защиты обвиняемого, подозреваемого.

В остальном же допрос свидетеля следователем и опрос лиц с их согласия защитником существенно отличаются друг от друга.

Во-первых, отличаются участники данных действий. Так, обязательными участниками допроса свидетеля является лицо, осуществляющее производство по делу (следователь, дознаватель) и свидетель. Лицо приобретает статус свидетеля после того, как следователь принял решение о вызове его на допрос. Если свидетель не достиг возраста шестнадцати лет, обязательно участие педагога или психолога (ч. 1 ст. 191 УПК РФ).

Участниками же опроса лиц с их согласия является защитник (п. 2 ч. 3 ст. 86 УПК РФ) и лицо, предположительно владеющее информацией, относящейся к делу.

Представляется необходимым наделить правом опрашивать лиц с их согласия и представителя потерпевшего. Как верно отмечал Ю.К. Якимович, у потерпевшего весьма ограниченные возможности по вовлечению в процесс тех сведений, на которых он основывает свою позицию [9, с. 98]. Закрепление же в УПК РФ права представителя потерпевшего собирать сведения, в том числе путем опроса лиц с их согласия, уравняют процессуальные возможности потерпевшего и обвиняемого в доказывании.

Во-вторых, допрос, в отличие от опроса лица защитником, - следственное действие, которое обеспечивается государственным принуждением. Защитник не может предупреждать опрашиваемых лиц об уголовной ответственности за дачу ложных показаний, а также за отказ от дачи показаний, не может обязать гражданина явиться для дачи объяснения. Как показал анализ практики, лица, обладающие информацией, необходимой для защиты обвиняемого, не всегда соглашаются на проведения опроса адвокатомзащитником, а если и соглашаются, зачастую уклоняются от явки в орган уголовного преследования или суд для дачи показаний, либо являются, но не подтверждают сообщенные ранее ими сведения.

Отсутствие при опросе лиц защитником таких гарантий, как предупреждение свидетеля об уголовной ответственности за отказ от дачи показаний и за дачу заведомо ложных показаний, разъяснения права не свидетельствовать против себя самого и своих близких родственников, было предметом рассмотрения Кон- ституционного Суда РФ. Так, согласно позиции Конституционного Суда РФ, наделение защитника таким правом означало бы придание - вопреки требованиям Конституции РФ и уголовно-процессуального законодательства - несвойственной ему процессуальной функции [10].

В-третьих, результаты допроса свидетеля имеют доказательственное значение, а сведения же, полученные в результате опроса защитником лиц, сами по себе не являются доказательствами. Доказательства в уголовном деле появляются после того, как они получены и зафиксированы в порядке, предусмотренном УПК РФ. Фиксация же доказательств - прерогатива должностных лиц, осуществляющих производство по делу.

Верховный Суд РФ в своих решениях неоднократно указывал, что из смысла ст. ст. 84 и 86 УПК РФ следует, что относимые к делу сведения, полученные защитником в результате опроса частных лиц..., нельзя рассматривать в качестве показаний свидетеля или потерпевшего. Они получены в условиях отсутствия предусмотренных уголовно-процессуальным законом гарантий их доброкачественности и поэтому могут рассматриваться в качестве оснований для вызова и допроса указанных лиц... или для производства других следственных действий по собиранию доказательств, а не как доказательства по делу $[11,12]$.

В-четвертых, порядок производства допроса следователем и фиксации результатов детально регламентирован в УПК РФ. Порядок же проведения опроса защитником лиц с их согласия законом не определен.

Между тем отсутствие четкой регламентации опроса лиц защитником, по нашему мнению, может негативно отразиться на результатах данного действия. Неверно выбранная защитником тактика при проведении опроса может повлиять на достоверность полученной информации.

В связи с тем, что при производстве допроса свидетелей следователем и опроса лиц защитником используются одни и те же познавательные приемы (расспрос, наблюдение), представляется возможным при проведении опроса взять за основу общую структуру допроса и использовать тактические приемы следователя.

В юридической литературе традиционно выделяют четыре основные стадии (этапа) проведения допроса: предварительная, свободного рассказа, вопросноответная и процессуального оформления полученных показаний (заключительная) [13, с. 197].

На первоначальной стадии защитник знакомится с опрашиваемым лицом и разъясняет ему, в связи с чем возникла необходимость проведения данного действия. Для того чтобы человек, которого опрашивает защитник, не чувствовал себя, как на допросе у следователя, целесообразно анкетные данные в протоколе опроса заполнить уже после проведения беседы.

На этапе свободного рассказа опрашиваемый, по предложению защитника, сообщает сведения об обстоятельствах, имеющих значение для защиты обвиняемого.

В рекомендациях Федеральной палаты адвокатов по реализации прав защитника, предусмотренных в ч. 3 ст. 86 УПК РФ, предлагается оформлять опрос в 
виде ответов на конкретные вопросы либо в форме свободного рассказа с постановкой уточняющих вопросов в конце его [4]. Однако не разъясняется, какие преимущества имеет одна форма перед другой. Между тем выбор тактики ведения опроса имеет большое значение.

Рекомендации по проведению допроса следователем достаточно хорошо обоснованы в юридической литературе. Например, В.Л. Кудрявцев пишет о преимуществах свободного рассказа: «...свободное изложение дает лицу возможность сосредоточиться, вспомнить отдельные обстоятельства, имеющие, по его мнению, значение для дела, ...ответы на вопросы в ходе допроса свидетеля не всегда могут осветить все стороны события, а реплики и замечания во время свободного рассказа способны привести его в замешательство и, как следствие этого, к путанице или не освещению им определенных обстоятельств, велика вероятность, что вопросами защитник может внушить определённый вариант ответов допрашиваемому лицу» $[14$, c. 152]. Однако, на наш взгляд, данные рекомендации имеют несомненную ценность и при организации опроса лиц защитником.

После этапа свободного рассказа следует вопросноответная часть. Что касается допроса свидетеля следователем, в Законе содержится запрет задавать наводящие вопросы (ч. 2 ст. 189 УПК РФ). Представляется, что данное требование закона обосновано. Как справедливо отмечал М.С. Строгович, в случае постановки наводящих вопросов, свидетель показывает не то, что он сам знает, а то, что ему подсказал следователь, особенно, если сам свидетель не помнит данного факта или помнит его не достаточно отчётливо, путается, не уверен в том, что было в действительности [15, с. 197].

По нашему мнению, необходимо законодательно аналогичное требование закрепить и для опроса защитником лица с его согласия. Так, психологи доказали, что на воспоминание о событиях может влиять и то, как задаются свидетелю вопросы, нечаянные и умышленные подсказки, содержащиеся в вопросах, очень часто могут оказать влияние на содержание памяти опраши- ваемого [16, с. 388]. Кроме того, тон, интонация, выражение лица, с которым задан вопрос, соответственно способны вызвать замешательство, сомнения, фантазии и, в конечном счете, исказить достоверность информации.

В вопросно-ответной стадии опроса, с целью получения интересующей информации защитнику необходимо задавать уточняющие и конкретизирующие вопросы. Данный подход позволяет выявить пробелы и противоречия в полученной информации и принять законные меры к их устранению. При определении тактики работы с конкретным гражданином защитник должен учитывать его психологические особенности, характер, темперамент и эмоциональное состояние. В любом случае, когда человеку задают преимущественно закрытые вопросы, он чувствует себя как на допросе у следователя, что мешает установлению психологического контакта и может препятствовать получению полной и достоверной информации. Поэтому необходимо чередовать открытые и закрытые вопросы.

На заключительном этапе защитник фиксирует результаты опроса. Согласно разработанным Федеральной палатой адвокатов методическим рекомендациям, ход и результаты опроса предлагается фиксировать в специальном документе. При этом акт опроса должен соответствовать требованиям, предъявляемым ст. ст. 189191 УПК РФ к протоколу допроса свидетеля [4].

Отдельный и принципиальный вопрос, требующий регламентации, - это возможность защитника использовать научно-технические средства для фиксации хода и результатов опроса лица. Это актуально, так как потенциальный свидетель не всегда может явиться в суд по объективным причинам (смерть, тяжелая болезнь, выезд за пределы страны и т.д.). Вышеуказанные обстоятельства могут быть непреодолимы, повлиять на возможность установления истины, привести к судебным ошибкам, поэтому необходимо законодательно закрепить данное право защитника. Однако вопросы регламентации применения защитником научно-технических средств требуют тщательной научной проработки и заслуживают самостоятельного рассмотрения.

\section{ЛИТЕРАТУРА}

1. Давлетов А. Право защитника собирать доказательства // Российская юстиция. 2003. № 7. С. 50-51.

2. Михайловская И.Б. Настольная книга судьи по доказыванию в уголовном процессе. М. : ТК Велби, Проспект, 2006.192 с.

3. Винберг А. Первая командировка // Литературная газета. 1969. № 41.

4. Методические рекомендации по реализации прав адвоката, предусмотренных п. 2 ч. 1 ст. 53, ч. 3 ст. 86 УПК РФ и п. 3 ст. 6 Федерального закона «Об адвокатской деятельности и адвокатуре в Российской Федерации» // Официальный сайт Федеральной палаты адвокатов PФ. URL: www.fparf.ru (дата обращения: 25.11.2018).

5. Рагулин А.В. О необходимости совершенствования регламентации института профессиональных прав адвоката-защитника в России // Адвокатская практика. 2014. № 2. С. 18-23.

6. Рагулин А.В. Регламентация прав адвоката-защитника на опрос лиц с их согласия и представление предметов и документов // Евразийская адвокатура. № 1(2). 2013. С. 50-52.

7. Шейфер С.А. Следственные действия. Основания, процессуальный порядок и доказательственное значение. М. : Юрлитинформ, 2004. $184 \mathrm{c}$.

8. Федеральный закон от 31.05.2002 № 63-Ф3 (ред. от 29.07.2017) «Об адвокатской деятельности и адвокатуре в Российской Федерации» // «Консультантплюс»:Справочно-правовая система. Версия Проф. (дата обращения: 25.11.2018).

9. Якимович Ю.К. Участники уголовного процесса. СПб. : Юридический центр, 2015. 176 с.

10. Определение Конституционного Суда РФ от 4 апреля 2006 г. № 100-О об отказе в принятии к рассмотрению жалобы гражданина А.А. Бугрова на нарушение его конституционных прав п. 2 ч. 3 ст. 86 УПК РФ // Вестник Конституционного Суда РФ. 2006. № 4.

11. Кассащионное определение Верховного Суда РФ от 21.09.2010 № 74-О10-29 // «Консультантплюс»: Справочно-правовая система. Версия Проф. (дата обращения: 25.11.2018). 
12. Определение Верховного Суда РФ от 08.12.2004 № 3-О04-42 // «Консультантплюс»: Справочно-правовая система. Версия Проф. (дата обращения: 25.11.2018).

13. Баев О.Я. Тактика уголовного преследования и профессиональной защит от него. М. : Экзамен, 2003. 432 с.

14. Кудрявцев В.Л. Актуальные вопросы участия адвоката-защитника в производстве допроса подсудимого, потерпевшего и свидетеля // Бизнес в законе. 2008. № 2. С. 146-161.

15. Строгович М.С. Курс советского уголовного процесса. М. : Госюриздат, 1968. 703 с.

16. Годфруа Ж. Что такое психология : в 2 т. М. : Мир, 1992. Т. 1. 496 с.

\section{SOME PROBLEMS OF THE DEFENDER'S QUESTIONING OF PERSONS WITH THEIR AGREEMENT}

Ugolovnaya yustitsiya - Russian Journal of Criminal Law, 2018, no. 12, pp. 92-95. DOI 10.17223/23088451/12/18

Veronika V. Yaselskaya, Tomsk State University (Tomsk, Russian Federation). E-mail: crim.just@mail.ru

Keywords: defence lawyer, investigator, preliminary investigation, interrogation of witnesses, questioning of persons with their agreement.

The Code of Criminal Procedure of the Russian Federation gives the defender the right to interview persons with their agreement. In practice, defence lawyers rarely use it. The lack of a clear regulation of the questioning of persons by the defender may adversely affect the results of this procedure. An incorrectly tactic chosen by a defender during the questioning negatively affects its results.

The article presents a comparative analysis of the interrogation of a witness by an investigator at the stage of preliminary investigation and the questioning of a person by a defence lawyer, their similarities and differences are revealed.

During the interrogation of witnesses by an investigator and the questioning of persons by a defence lawyer, the same cognitive methods (questioning, observation) are used; in this connection, it is advisable for a defence lawyer to take the general structure of interrogation as a basis and use similar tactics.

The correct tactics of questioning affects the completeness and accuracy of the information received by the defender.

\section{References}

1. Davletov, A. (2003) Pravo zashchitnika sobirat' dokazatel'stva [The right of the defender to collect evidence]. Rossiyskaya yustitsiyaRussian Justitia. 7. pp. 50-51.

2. Mikhaylovskaya, I.B. (2006) Nastol'naya kniga sud'i po dokazyvaniyu v ugolovnom protsesse [Handbook of a judge for proving in criminal proceedings]. Moscow: TK Velbi, Izd-vo Prospekt.

3. Vinberg, A. (1969) Pervaya komandirovka [First business trip]. Literaturnaya gazeta. 41.

4. Official site of the Federal Chamber of Lawyers of the Russian Federation. (n.d.) Methodological recommendations on the implementation of the rights of a lawyer, provided for by Paragraph 2 of Part 1 of Art. 53, Part 3 of Art. 86 of the RF Code of Criminal Procedure and Paragraph 3 of Art. 6 of the Federal Law "On Lawyers'Activities and the Bar in the Russian Federation". [Online]. Available from: www.fparf.ru. (Accessed: 25.11.2018). (In Russian).

5. Ragulin, A.V. (2014) O neobkhodimosti sovershenstvovaniya reglamentatsii instituta professional'nykh prav advokata-zashchitnika $\mathrm{v}$ Rossii [On the need to improve the regulation of professional rights of defence lawyer in Russia]. Advokatskaya praktika. 2. pp. 18-23.

6. Ragulin, A.V. (2013) Reglamentatsiya prav advokata-zashchitnika na opros lits s ikh soglasiya i predstavlenie predmetov i dokumentov [The regulation of the rights of defence lawyer to question persons with their agreement and the presentation of objects and documents]. Evraziyskaya advokatura - Eurasian Advocacy. 1(2). pp. 50-52.

7. Sheyfer, S.A. (2004) Sledstvennye deystviya. Osnovaniya, protsessual'nyy poryadok i dokazatel'stvennoe znachenie [Investigative actions. Grounds, procedural order and evidentiary value]. Moscow: Yurlitinform.

8. Russian Federation. (2017) Federal'nyy zakon ot 31.05.2002 N 63-FZ (red. ot 29.07.2017) "Ob advokatskoy deyatel'nosti i advokature v Rossiyskoy Federatsii” " [Federal Law No. 63-FZ of 31.05.2002 (as amended on July 29.2017) "On Lawyers' Activity and the Bar in the Russian Federation"]. Moscow: AO "Konsul'tantPlyus".

9. Yakimovich, Yu.K. (2015) Uchastniki ugolovnogo protsessa [Participants in the criminal procedure]. St. Petersburg: Izdatel'stvo "Yuridicheskiy tsentr".

10. Vestnik Konstitutsionnogo Suda RF. (2006) Opredelenie Konstitutsionnogo Suda RF ot 4 aprelya 2006 g. N 100-O ob otkaze v prinyatii $\mathrm{k}$ rassmotreniyu zhaloby grazhdanina A.A. Bugrova na narushenie ego konstitutsionnykh prav p. 2 ch. 3 st. 86 UPK RF [Determination of the Constitutional Court of the Russian Federation No. 100-O of April 4, 2006, on the refusal to accept complaints from citizen A.A. Bugrov on the violation of his constitutional rights by Paragraph 2 of Part 3 of Article 86 of the RF Code of Criminal Procedure]. 4.

11. Russian Federation. (2010) Kassatsionnoe opredelenie Verkhovnogo Suda RF ot 21.09.2010 N 74-O10-29 [Cassation determination of the Supreme Court of the Russian Federation No. 74-O10-29 of September 21, 2010]. Moscow: AO “Konsul'tant plyus".

12. Russian Federation. (2004) Opredelenie Verkhovnogo Suda RF ot 08.12.2004 N 3-O04-42 [Determination of the Supreme Court of the Russian Federation No. 3-O04-42 of December 8, 2004]. Moscow: AO "Konsul'tant plyus".

13. Baev, O.Ya. (2003) Taktika ugolovnogo presledovaniya i professional'noy zashchit ot nego [The tactics of criminal prosecution and professional protection against it]. Moscow: Izdatel'stvo "Ekzamen".

14. Kudryavtsev, V.L. (2008) Aktual'nye voprosy uchastiya advokata-zashchitnika v proizvodstve doprosa podsudimogo, poterpevshego i svidetelya [Topical issues of the participation of defence lawyer in the interrogation of the defendant, the victim and the witness]. Biznes $v$ zakone. 2. pp. 146-161.

15. Strogovich, M.S. (1959) Kurs sovetskogo ugolovnogo protsessa [A course of the Soviet criminal procedure]. Moscow: Gosyurizdat.

16. Godefroid, J. (1992) Chto takoe psikhologiya: $v 2 t$. [What is psychology: in 2 vols]. Translated from French. Vol. 1. Moscow: Mir. 